\title{
Test Plan for Digface Chemical and Radiation Assay System
}

\author{
D. W. Akers \\ Published July 1993
Idaho National Engineering Laboratory
EG\&G Idaho, Inc.
Idaho Falls, Idaho 83415

Prepared for the

U.S. Department of Energy

Office of Environmental Restoration and Waste Management

Under DOE Idaho Operations Office

Contract DE-AC07-76ID01570

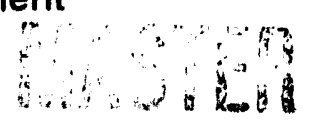




\section{Test Plan for Digface Chemical and Radiation Assay System}

EGG-WTD-10813

Prepared by

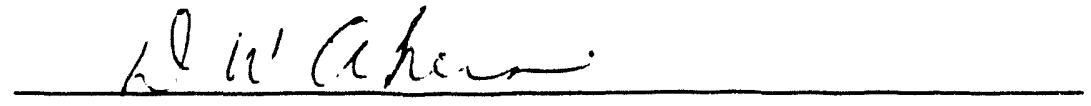

D. W. Akers, Scientific Specialist Nuciear and Radiological Physics

Reviewed by

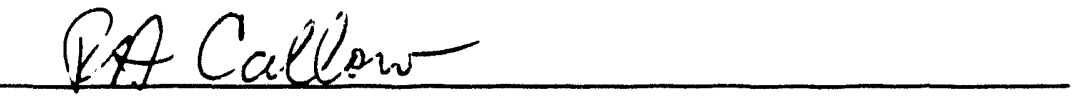

R. A. Callow, Project Manager

Buried Waste Integrated Demonstration

Approved by

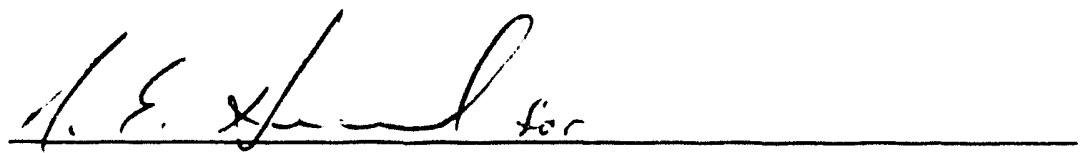

K. M. Kostelnik, Coordinator

Buried Waste Integrated Demonstration
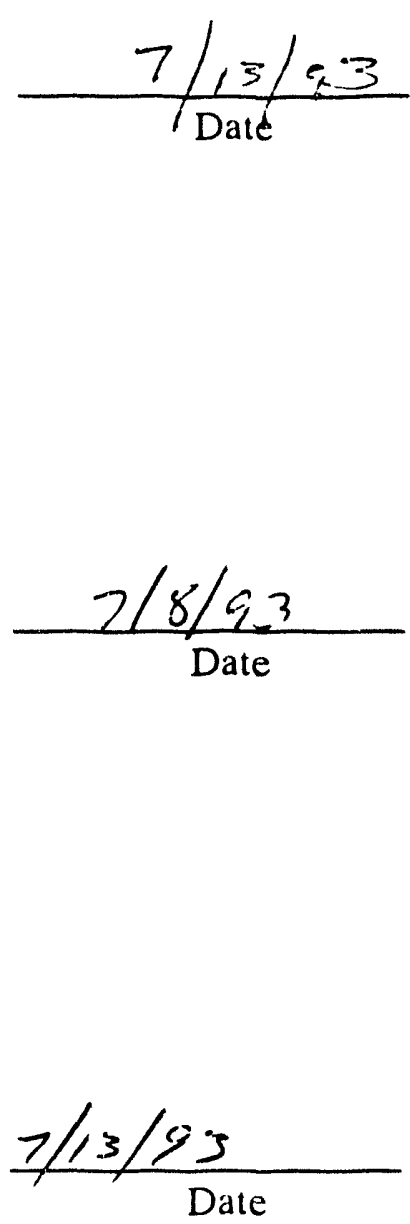


\begin{abstract}
The Digface Chemical and Radiation Assay System (CRAS) Project will develop a sensor using Prompt Gamma Neutron Activation Analysis (PGNAA) that can detect the present of hazardous chemicals and radioactive materials. The CRAS is being designed for in situ assay of closed drums and contaminated soils for gamma-ray emitting radionuclides and hazardous elements. The CRAS is based upon the use of ${ }^{252} \mathrm{Cf}$ PGNAA with a germanium gamma-ray spectrometer as the analyzer. Tasks being performed include determining detection limits for a number of hazardous chemicals and assessing matrix and transmission effects through soil. Initial analyses suggest that the technique is applicable to a number of hazardous materials such as trichloroethane and carbon tetrachloride.
\end{abstract}




\section{CONTENTS}

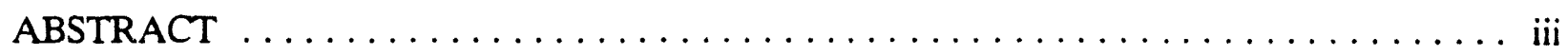

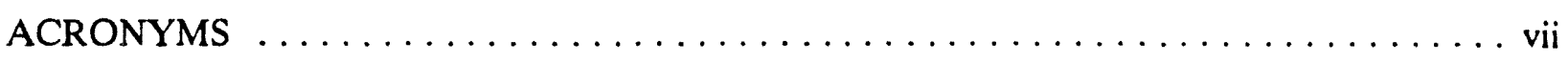

1. INTRODUCTION $\ldots \ldots \ldots \ldots \ldots \ldots \ldots \ldots \ldots \ldots \ldots \ldots \ldots \ldots \ldots \ldots \ldots \ldots$

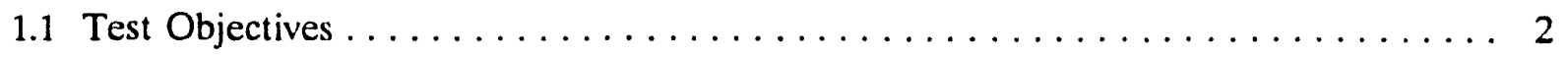

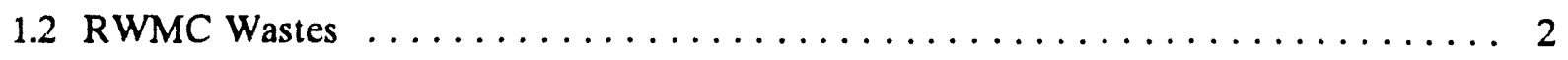

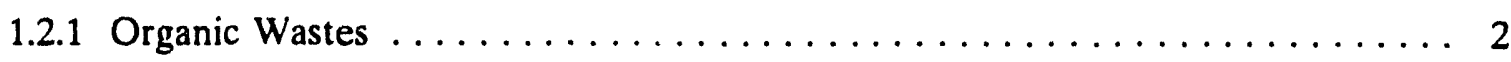

1.2.2 Metals/norganics $\ldots \ldots \ldots \ldots \ldots \ldots \ldots \ldots \ldots \ldots \ldots \ldots \ldots \ldots \ldots \ldots \ldots \ldots \ldots \ldots, 3$

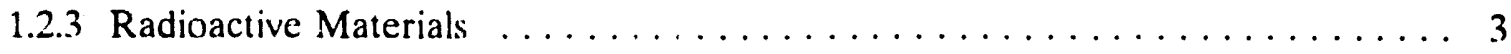

2. TEST PLAN ORGANIZATION AND RESPONSIBILITIES $\ldots \ldots \ldots \ldots \ldots \ldots$

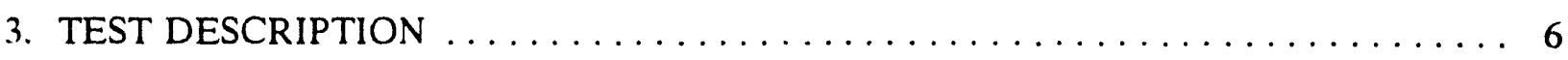

3.1 Monte Carlo Analysis . . . . . . . . . . . . . . . . . . . . . . . 6

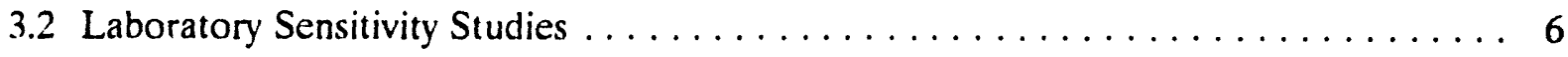

3.3 CRAS Conceptual Design Report $\ldots \ldots \ldots \ldots \ldots \ldots \ldots \ldots \ldots \ldots$

3.4 Technology Demonstration $\ldots \ldots \ldots \ldots \ldots \ldots \ldots \ldots \ldots \ldots \ldots \ldots$

4. SEQUENCE OF ACTIVITIES $\ldots \ldots \ldots \ldots \ldots \ldots \ldots \ldots \ldots \ldots \ldots \ldots \ldots \ldots \ldots \ldots$

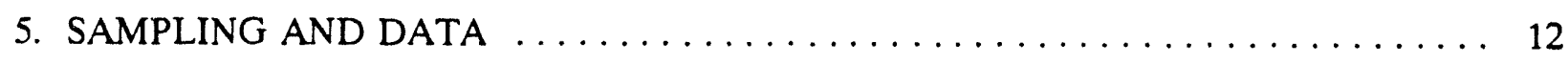

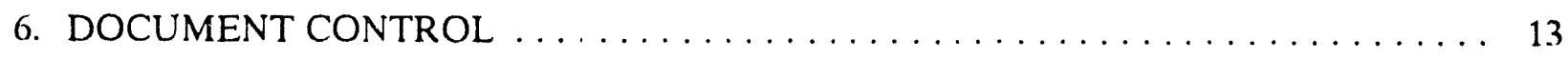

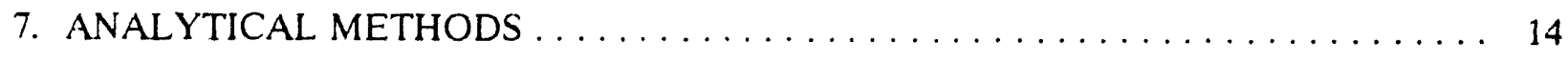

8. DATA REDUCTION, VALIDATION, AND VERIFICATION $\ldots \ldots \ldots \ldots \ldots \ldots$

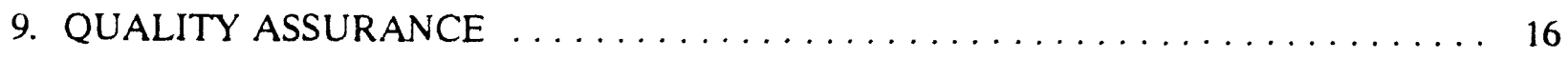

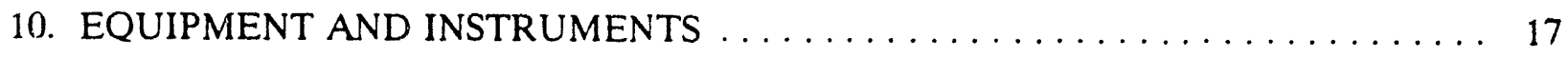

11. SUPPLIES, UTILITIES, AND FACILITIES $\ldots \ldots \ldots \ldots \ldots \ldots \ldots \ldots \ldots$

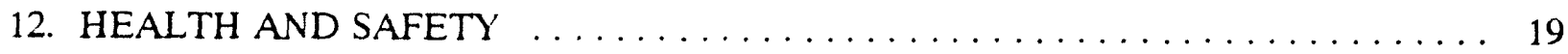


13. RESIDUALS MANAGEMENT $\ldots \ldots \ldots \ldots \ldots \ldots \ldots \ldots \ldots \ldots \ldots \ldots \ldots$

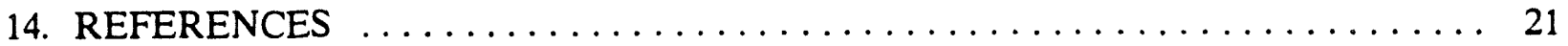

\section{FIGURE}

1. Organizational responsibilities

\section{TABLES}

1. Monte Carlo analysis of CRAS detection sensitivities $\ldots \ldots \ldots \ldots \ldots \ldots \ldots \ldots$

2. Laboratory sensitivity study test $\operatorname{matrix} \ldots \ldots \ldots \ldots \ldots \ldots \ldots \ldots \ldots \ldots \ldots$ 


\section{ACRONYMS}

BWID Buried Waste Integrated Demonstration

CRAS Chemical and Radiation Assay System

DOE U. S. Department of Energy

DOE-ID U. S. Department of Energy Idaho Operations Office

EDF Engineering design file

Ge Germanium

INEL Idaho National Engineering Laboratory

ISU Idaho State University

MCNP Monte Carlo Neutron and Photon

OAC Office of Arms Control

PGNAA Prompt Gamma Neutron Activation Analysis

PINS Portable Isotopic Neutron System

RWMC Radioactive Waste Managemenı Complex

SDA Subsurface Disposal Area

TRA Test Reactor Area

WTD Waste Technology Development 


\section{Test Plan for Digface Chemical and Radiation Assay System}

\section{INTRODUCTION}

Unremediated burial sites currently exist throughout the U. S. Department of Energy (DOE) complex. For example, the Idaho National Engineering Laboratory (INEL) has 2 million cubic feet of transuranic ivaste buried in shallow land burial that is commingled with up to 10 million cubic feet of soil. Remediation of buried waste represents a challenging technical problem because of the inadequate characterization of disposed waste and associated hazards and the unique technical problems associated with remediation of mixed wastes. An approach to these challenges was proposed that incorporates characterization of the waste into the retrieval process. Characterization at the digface during retrieval operations allows a more adaptive approach to the characterization problem because monitoring is included as part of operations and can be used to identify hazards that are not addressed by initial, standard, site characterization methods. This system would allow cleanup of hazardous waste sites to begin even in cases where buried hazards are poorly documented and characterization efforts have failed. The Buried Waste Integrated Demonstration (BWID) Program is funding a project that will demonstrate the feasibility and subsequently develop a digface characterization system.

Several sensors are being evaluated for potential inclusion into the digface characterization system. One of these is the Digface Chemical and Radiation Assay System (CRAS). The CRAS Project will develop a sensor that can be used to detect the presence of hazardous chemicals and radioactive materials at disposal sites where materials are being excavated for environmental, safety, and health or regulatory reasons.

The sensor will be designed to allow in situ assay of closed drums and contaminated soils for both gamma-ray emitting radionuclides and hazardous elements. The CRAS is based upon the use of ${ }^{252} \mathrm{Cf}$ Prompt Gamma Neutron Activation Analysis (PGNAA) with a germanium (Ge) gamma-ray spectrometer. $A{ }^{252} \mathrm{Cf}$ source assembly and portable Ge spectrometer are currently being used by the DOE Office of Arms Control (OAC) and Nonproliferation to assay chemical agents within munitions and storage containers. This OAC system is the basis for the diglace sensor and must be scaled up to meet projected digface requirements for detection limits and detection through soils. At the INEL, several field demonstrations of this developing technology will be funded using DOE OAC funds. This task is separate from the Waste Technology Development (WTD) project.

A survey of chemical inventory logs from the Radioactive Waste Management Complex (RWMC) Subsurface Disposal Area (SDA) indicates that the CRAS is applicable to resolving questions concerning the distribution of radioactive and chemical waste at the RWMC. This evuluation suggests, for example, that the CRAS will he useful in identifying and discriminating between organic, metal, and other types of waste at the RWMC and in minimizing the contamination of uncontaminated waste and soil.

This objective of this test plan is to evaluate the feasibility of the technique for this application and develop a conceptual design of the diglace CRAS system. Success of this leasibility study is 
defined as determining the sensitivity for key element (e.g., chlorine) configurations that are specific to the digface and developing a conceptual design of the digface CRAS.

\subsection{Test Objectives}

This section identifies and discusses the test objectives for the CRAS project as it relates to the digface program. The general objectives are to evaluate the applicability of PGNAA for characterizing waste for hazardous chemical constituents at the RWMC and to perform the necessary developmental research needed to design the CRAS for use in the integral digface sensor package. Based on these overall objectives, the specific test objectives for this effort are

- Determine the sensitivity of PGNAA for various elements expected to be found in RWMC wastes

- Assess matrix (e.g., soil, container, and liner material) effects on the detection limit for important elements

- Determine the requirements for scaling up the current portable system for use as an integral part of the digface sensor package.

- Develop a design requirement for the digface CRAS that assesses detection limits, scan speeds, and specific applications.

The identified research will be used to make an evaluation of the limitations and strengths of the CRAS and its application as a part of the digface sensor system.

\subsection{RWMC Wastes}

An evaluation has been performed of the volume and quantities of wastes at the RWMC to assess the applicability of the CRAS to these wastes. The wastes can be divided into three categories that are not necessarily distinct but may be present in bulk amounts: organic wastes, metals, and radioactive wastes.

\subsubsection{Organic Wastes}

An assessment of the organic wastes at the RWMC indicates that the primary hazardous organic chemical waste at the RWMC is the plutonium-contaminated sludge from the Rocky Flats Plant. This sludge contains high concentrations of carbon tetrachloride and trichloro compounds. There are about $7.6 \times 10^{5} \mathrm{~L}$ of these chlorine-containing compounds at the RWMC, either in intact barrels or in deposits in the waste and surrounding earth where barrels or containers have disintegrated. Due to the expected large concentrations of chlorine, which has a large neutron capture cross section present in the plutonium-containing sludge, the CRAS should be sufficiently sensitive to positively identify chlorine in thesc wastes at concentrations of approximately $100 \mathrm{~g} / \mathrm{barrel}$. This technique will provide a good initial screening lechnique to identify and discriminate the Rocky Flats sludge that is expected to contain substantially larger amounts of plutonium than other wastes. 
Other major hazardous organic wastes at the RWMC are the contaminated Texaco Regal oil $\left(4.7 \times 10^{5} \mathrm{~L}\right)$ that is mixed with the chlorinated compounds and can also be identified by the presence of chlorine. Other organics that are present in the SDA are small amounts of miscellaneous oils, alcohols, gasoline, VERSENE (ethylenediaminetetraacetic acid) and various other nitrogen containing organic acids. The miscellaneous oils, alcohols, and gasoline are not detectable by CRAS because only hydrogen, oxygen, and carbon are present; however, those containing nitrogen may be detectable.

\subsubsection{Metals/Inorganics}

Approximately $22 \mathrm{wt} \%$ of the radioactive waste at the RWMC is metals, and there are quantities of other inorganics present. The CRAS has the ability to definitively discriminate between barrels containing quantities of iron and other constituents of steel from those filled with nonferrous metals or nonmetals. Specific elements present at the RWMC for which the CRAS may provide information if encountered in sufficient concentrations are iron, mercury, cobalt, nickel, manganese, and potassium (from $\mathrm{NaK}$ ), with lesser sensitivities for aluminum. molybdenum, and lead. Of these, mercury and lead are considered hazardous. The presence of large quantities of these elements may indicate the presence of some radionuclides that cannot be detected by other means but are generally associated with specific elements (e.g., ${ }^{63} \mathrm{Ni}$ and cohalt). The analysis for structural (metal) components will allow waste containers to be discriminated from those containing large amounts of metal (primarily steel and Inconel) and those containing other types of metal or debris.

Inorganic constituents present in smaller quantities at the RWMC that may be assayed and discriminated using the CRAS include salts containing chlorine, lanthanides, and nitrates.

\subsubsection{Radioactive Materials}

The primary radioactive materials for which analyses can be performed are the gamma-ray emitting radionuclides including primary fission products $\left({ }^{137} \mathrm{Cs}\right.$. which may be an indicator of the presence of other radionuclides that are not gamma-ray emitters) such as those identified in the summary of the radioactive contents of the RWMC. Another gamma emitter, ${ }^{60} \mathrm{Co}$. is an indicator of the presence of other radionuclides that would be produced in activated metals. In addition, some isotopes of plutonium (including ${ }^{239} \mathrm{Pu}$ ), americium, and uranium may be detectable. These elements produce relatively low energy gamma-rays and, consequently, may not be detected if sufficient shiclding is present.

The following section discusses the lest that will be pertormed to complete the proof of principal and sensitivity study for the CRAS. The test plan may be modified when results indicate that sufficient data have been acquired in a particular area or that other data may be needed. The product of this project, the summary conceptual design report, will address all aspects of the test plan as described in this report. 


\section{TEST PLAN ORGANIZATION AND RESPONSIBILITIES}

This work is performed at the INEL with funding provided by the Office of Technology Development. The personnel organization supporting this project is shown in Figure 1.

- The program manager establishes levels of funding, defines project scope and direction, and is responsible for final acceptance of all work performed under this contract.

- The U. S. Department of Energy Idaho Operation Office (DOE-ID) Program Manager monitors all work required including cost, scope, budget, and schedule of work.

- The EG\&G Idaho, Inc. project manager tracks budgets, related schedules, and work performed to ensure that the completed work meets the requirements of the contract. Modifications to the test plan will be developed by the principal investigator and reviewed by the program manager. All changes will be documented and recorded in the engineering design file and project file.

- The principal investigator ensures that all work performed under this contract meets the contract requirements. He is responsible for ordering equipment, conducting research, ensuring data quality and integrity, safety and environmental compliance, making changes to the test plan and documenting the changes in the project file. He is also responsible for training operators and ensuring that measurements are being performed correctly.

Other staff within Nuclear and Radiological Physics will be used to perform measurements, assemble hardware, and prepare sample standards. 

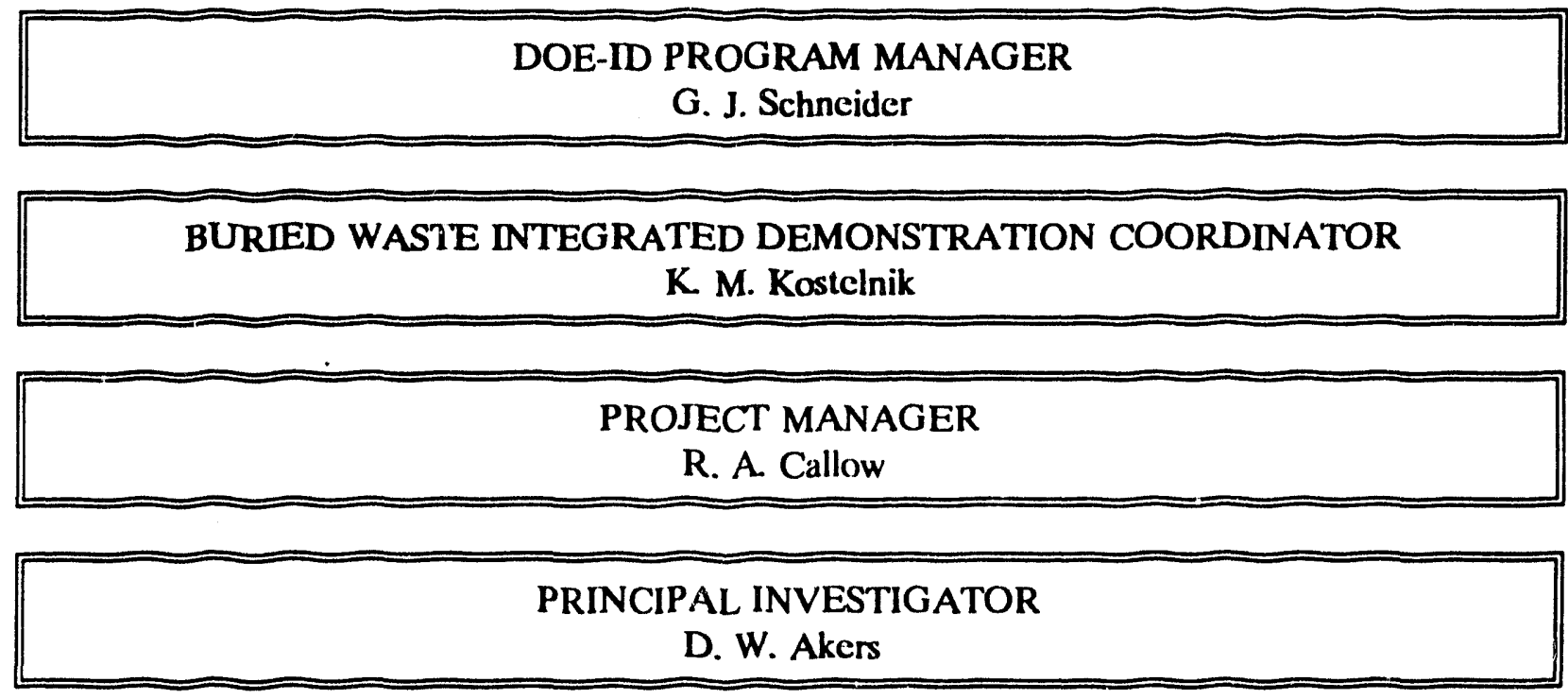

Figure 1. Organizational responsibilities. 


\section{TEST DESCRIPTION}

The objective of fiscal year 1993 test plan is to perform sufficient research to assess the sensitivity of the system for specified elements and to develop a verifiable conceptual design for the CRAS. Technical tasks to be completed are (a) complete the Monte Carlo' analysis of the detector response for the various elements that have been identified as being present at the RWMC, (b) perform laboratory evaluations of sensitivity for the various elements, (c) perform several field demonstrations (funded by DOE OAC), and (d) complete the conceptual design report for the CRAS. In addition, all laboratory safety requirements will be addressed. Key elements of this project are summarized in the sections below

\subsection{Monte Carlo Analysis}

Preliminary calculations are being performed to assess the CRAS system sensitivity for various sample depths, shielding, thickness, and elements for which analyses can be perlormed. The test matrix for these calculations is shown in Table 1. The specific calculations in process are

- Evaluate the 55-gal drum geometry with distributed concentrations of the identified elements (see Table 1). The nominal concentration for the first analysis is 3 wt\% of each element. Concentrations for elements with lower neutron capture cross sections will be modified based on these results.

- Assess effects of soil thickness on detection sensitivity and evaluate the effects of water content on the detection limit.

- Assess the effects of higher neutron energy spectrums (i.e., greater than ${ }^{252} \mathrm{Cf}$ ) on the elemental detection limit. Specific energies to be addressed are an isotopic source with an average neutron energy of about 4.5 and $14 \mathrm{MeV}$ neutrons.

- Assess the detection limit for localized bulk clemental content in a 55-gal drum. Initial calculations have been performed using $500 \mathrm{~g}$ of carbon tetrachloride located in the center of the drum.

The results of the Monte Carlo evaluations will be used to guide the laboratory and field measurements. Thirty-one tests are identified, including an analysis for the transmission of ${ }^{137} \mathrm{Cs}$ and ${ }^{60} \mathrm{Co}$. Four to five analyses will be perlormed lor each lest to optimize the detection limits for specific elements. The data will be presented in the report as weight percent of the element detected based on a known neutron intluence. Initial results indicate that $3 \mathrm{wt} \% \mathrm{c}$ of chlorine in soil in a 55 -gal drum geometry is easily detectable using a relatively short count time ( $<5$ minutes).

\subsection{Laboratory Sensitivity Studies}

Based in part on the Monte Carlo analysis results, appropriate simulants are being developed to complete the laboratory studies listed in Table 2. Specific simulant geometries to be developed 
Table 1. Monte Carlo analysis of CRAS detection sensitivities.

$\begin{array}{lllllllllll}\text { Analysis task } & \mathrm{Cl} & \mathrm{N} & \mathrm{Hg} & \mathrm{Pb} & \mathrm{Fe} & \mathrm{Co} & \mathrm{Mn} & \mathrm{K} & \mathrm{Cd}\end{array}$

\begin{tabular}{|c|c|c|c|c|c|c|c|c|}
\hline Distributed geometry (55 gal) & $\mathrm{x}$ & $\mathrm{x}$ & $\mathrm{x}$ & $\mathrm{x}$ & $x$ & $\mathbf{x}$ & $\mathbf{x}$ & $\mathrm{x}$ \\
\hline Transmission (55 gal), 12 in. soil & $\mathbf{x}$ & $x$ & $\mathrm{x}$ & $\mathrm{x}$ & $\mathbf{x}$ & - & - & - \\
\hline Transmission ( $55 \mathrm{gal}$ ), 6 in. soil & $\mathrm{x}$ & $\mathbf{x}$ & $\mathrm{x}$ & $\mathrm{x}$ & - & - & - & 一 \\
\hline Soil saturation & $\mathbf{x}$ & $\mathbf{x}$ & $x$ & - & - & - & - & 一 \\
\hline Average energy, $4.5 \mathrm{MeV}$ & $x$ & $\mathbf{x}$ & - & - & - & - & - & 一 \\
\hline $14 \mathrm{MeV}$ neutrons & $\mathbf{x}$ & $\mathbf{x}$ & - & - & - & - & - & - \\
\hline Bulk sensitivity & $\mathrm{x}$ & $\mathrm{x}$ & - & - & - & - & - & - \\
\hline${ }^{137} \mathrm{Cs}$ and ${ }^{60} \mathrm{Co}$ & 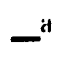 & - & - & - & - & - & - & - \\
\hline
\end{tabular}

a. Parametric calculations will be performed 10 asisess ${ }^{137} \mathrm{Cs}$ and ${ }^{60} \mathrm{Co}$ transmission through 55 -gal drums and soil thicknesses. A few measurements will be performed to validate the calculations.

are 55-gal drums, soil containers for shielding ( 6 and 12 in. thick), and saturated soil ( 3 and 6 in. thick).

The test matrix listed in Table 2 addresses parameters needed to substantially define the CRAS conceptual design. Specifically, they are detection limits for elements present in hazardous compounds, matrix effects, and the effects of liners and containers on the detection limit for specific elements. Specific laboratory tests to be completed are

- Measurements will be performed on samples containing key elements in a distributed geometry in a defined RWMC soil matrix. It is expected that nonhazardous constituents (e.g. salt and ammonium nitrate) can be used for most elements. In cases where nontiazardous constituents cannot be mixed into the soil matrix, the elemental material (e.g., lead) will be placed in small containers ur hags and distributed evenly in the soil at reproducible locations (i.e., a soil test barrel will be prepared that contains a matrix of thin wall polyethylene pipes into which hazardous material sample containers can be inserted).

- Transmission measurements with the source and detector separated from the sample by 6 to 12 in. of soil will be performed for representative elements (see Table 1) in the distributed geometry to assess detection limits at the digface. Normal soil saturation in INEL soils will be evaluated to assess detection limits for these conditions. Soil saturation levels of 25 and $50 \%$ will be addressed. 
Table 2. Laboratory sensitivity study test matrix. ${ }^{\mathrm{a}}$

$\begin{array}{lllllllllllll}\text { Laboratory tests } & \mathrm{Cl} & \mathrm{N} & \mathrm{Hg} & \mathrm{Pb} & \mathrm{SS}^{\mathrm{b}} & \mathrm{In}^{\mathrm{b}} & \mathrm{Fe} & \mathrm{Co} & \mathrm{Mn} & \mathrm{K} & \mathrm{Cd}\end{array}$

\begin{tabular}{|c|c|c|c|c|c|c|c|c|c|c|c|}
\hline $\begin{array}{l}\text { Distributed geometry } \\
\text { (55-gal) }\end{array}$ & $\mathbf{x}$ & $-^{c}$ & $-^{c}$ & $\mathrm{x}$ & $x$ & $-c$ & $-^{c}$ & $-^{c}$ & $-^{c}$ & $-^{c}$ & $-^{c}$ \\
\hline $\begin{array}{l}\text { Transmission, 12-in. } \\
\text { soil }\end{array}$ & $\mathbf{x}$ & $-^{c}$ & $-^{c}$ & $\mathrm{x}$ & $x$ & - & - & - & - & - & - \\
\hline $\begin{array}{l}\text { Transmission, } 6 \text { in. } \\
\text { soil }\end{array}$ & $\mathbf{x}$ & $-^{c}$ & $-^{c}$ & - & $x$ & - & 一 & - & - & - & - \\
\hline Bulk sensitivity & $\mathbf{x}$ & - & - & - & $x$ & - & - & - & - & - & - \\
\hline Soil saturation & $-{ }^{d}$ & - & - & - & - & - & - & - & - & - & - \\
\hline Interference effects & $x$ & - & - & - & $x$ & - & - & - & - & - & - \\
\hline $\begin{array}{l}\text { Distributed geometry } \\
\text { (5-gal can) }\end{array}$ & $-{ }^{d}$ & $-d$ & - & - & $-d$ & - & - & - & - & - & - \\
\hline $14 \mathrm{MeV}$ neutrons ${ }^{e}$ & $-{ }^{d}$ & - & $-d$ & - & $-^{d}$ & - & - & - & - & - & - \\
\hline $\begin{array}{l}{ }^{137} \mathrm{Cs} \text { and }{ }^{60} \mathrm{Co} \\
\text { transmission }\end{array}$ & - & - & - & - & $-f$ & - & - & - & - & - & - \\
\hline
\end{tabular}

a. Test matrix may be modified based on initial test results to eliminate elements for which results indicate that the required sensitivity is not possible or if higher concentrations are required.

b. Stainless steel and Inconel 304 stainless will be measured as it is most common.

c. Geometry or element will be addressed using calculational methods.

d. Task deferred.

e. If required, tests with higher energy or $14 \mathrm{MeV}$ ncutrons will be performed at the ldaho State University (ISU) facility (none are currently planned). These tests may he performed if there is not adequate sensitivity through 12 in. of soil.

f. Simple transmission measurements will he made to assess the effects of soil thickness on the gamma-ray transmission through soil and 55-gal drum material. 
- Interferences that may affect the detection limit for the identified elements will be assessed. These include interferences such as chlorinated plastic in the waste and spectral interferences in the gamma-ray spectrum that may be caused by normal waste constituents. The effect of chlorinated plastics on the chlorinated waste measurements will be assessed. Signatures for chlorinated waste and plastics will be developed, and potential gamma-ray spectrum interferences will be identified during the test phase.

- Detection limit measurements for ${ }^{137} \mathrm{Cs}$ and ${ }^{60} \mathrm{Co}$ in waste will be performed for comparison with Monte Carlo analyses to develop a nomogram that defines source size and the detection limit through several soil thicknesses.

As noted in Table 1, some tasks will be deferred until next year. If there is available time, these tasks will be addressed by means other than calculational methods. Other tasks that would be performed to complete the full laboratory assessment of sensitivities are listed below.

- Address more elements in the distributed geometry. The results for these elements will be extrapolated from the measured elements and Monte Carlo data.

- Address the 5-gal can geometry to assess detection limits for this geometry. Some waste at RWMC is currently contained in 5-gal cans.

- Perform measurements for a range of soil saturation levels to develop a nomogram for various saturation levels. Measurements will be performed for 0,25 , and $50 \%$ saturation.

- If sensitivity levels achievable with a ${ }^{252} \mathrm{CF}$ source for some elements are determined to be too low, perform measurements with higher energy or $14 \mathrm{MeV}$ neutrons to cornplete the conceptual design study. These measurements would be performed at ISU to determine the detection limits for the 55-gal drum geometry.

\subsection{CRAS Conceptual Design Report}

The conceptual design of the final digface CRAS will be documented in a report that will provide a complete description of the proposed system including neutron source requirements, shielding, hardware design, and sensitivities lor various elements (see Tables 1 and 2) in defined geometries, such as 5 and 55-gal drums, soil saturation eflects on sensitivity, and requirements for preparing the system for field use.

\subsection{Technology Demonstration}

OAC funding will be used to perform demonstration measurements at the INEL based on initial results of the WTD program. These tasks are complementary to the workscope identified in this test plan but are not within the WTD workscope. The proposed measurements and INEL 
locations are (a) assess the chlorine content of boxes of low-level waste containing combustibles for incineration at the Waste Experimental Reduction Facility, (b) perform an assay of characterized core bores or chlorinated waste barrels to compare the results with radiochemical assays, and (c) perform assay of other wastes contaminated with polychlorinated biphenyls or other chlorinated hazardous wastes. 


\section{SEQUENCE OF ACTIVITIES}

The sequence of activities for the test series is as follows with nominal completion dates for key activities. This assumes that review of the test plan is completed in one week.

Task

1. Complete Monte Carlo measurements

2. Complete laboratory measurements

3. Complete conceptual design report

4. Complete OAC field demonstrations
Complction date

May 15

August 30

September 15

November 30

This task breakdown structure and milestones may be modificd based on delays at the RWMC and Test Reactor Area (TRA) laboratory. 


\section{SAMPLING AND DATA}

All documents and reports will be placed in an engineering design file (EDF). Laboratory records will be maintained in the laboratory notebook, and the spectral data will be documented by a memo in the EDF. Appropriate backup on tape for stored data will protect data from loss. These data will be placed in the project file.

Gamma spectrometry data will be summarized in reports in the EDF alcng with the Monte Carlo analysis results for the calculated sensitivities. The gamma spectrometry data will also be retained on tape or stored on computer disk. 


\section{DOCUMENT CONTROL}

This section addresses data control, test plan modifications, and other documents. Raw gamma spectrometry data will be stored on tape with summaries of the results in the EDF. Periodic EDF submittals will be transmitted to the project manager and EDF. If modifications to the test plan are required, they will be documented and copies transmitted to the project manager and placed in the EDF. 


\section{ANALYTICAL METHODS}

The principal analytical methods to be used in this study are the Monte Carlo Neutron and Photon (MCNP) Transport Code, which is a documented code with appropriate verification, and the gamma-ray spectrometry analysis codes OMNIGAM ${ }^{2}$ and VAXGAP. ${ }^{3}$ The OMNIGAM code is a product of EG\&G ORTEC, and the VAXGAP code was developed at the INEL. In both cases, energy calibration will be performed by least squares fitting of gamma-ray peaks of well-known energies with either a linear or quadratic function. Neutron capture gamma-ray energies will be obtained from Reference 1. 


\section{DATA REDUCTION, VALIDATION, AND VERIFICATION}

As discussed in Section 7, all data will be analyzed with the OMNIGAM or VAXGAP gamma spectrometry analysis codes. These codes have been demonstrated and have shown to provide correct and accurate results when used on known geometries. Whenever possible, measurements will be compared with MCNP calculated results. Validation of the data will be done through comparisons with code calculated results and comparisons between measurements of samples with known composition. Acceptance criteria is defined as data obtained in a defined, reproducible geometry. Data are typically accepted where counting statistics are $\leq .30 \%$. Where possible, comparisons with calculated Monte Carlo data will be performed and documented. 


\section{QUALITY ASSURANCE}

Quality assurance for this program will he through comparisons between measurements and the actual compositional makeup (key elements present) of the sample. Periodic (20\%) duplicate measurements will be performed to demonstrate that the data are reproducible. All procedures, data, and reports generated in this program (including the final report) will be reviewed by the BWID project manager and senior technical personnel. This review meets INEL requirements for quality assurance. 


\section{EQUIPMENT AND INSTRUMENTS}

Specific instruments to be used during this study are the Portable Isotopic Neutron System (PINS) equipment developed for the DOE OAC, an IBM 486 computer system for MCNP code analyses, and VAX workstations for the VAXGAP analysis of results. The PINS system provided by the OAC is composed of a 386 notebook personal computer, the ORTEC NOMAD multichannel analyzer system, a neutron source with appropriate shielding, and the EG\&G ORTEC OMNIGAM gamma-ray spectrometry analysis code. Isotopic ${ }^{252} \mathrm{Cf}$ sources have been obtained for these measurements. 


\section{SUPPLIES, UTILITIES, AND FACILITIES}

The required equipment for this test program are the various sample geometries (e.g., 55-gal drum) that have been identified, standard materials, PINS system, and laboratory space at TRA. Appropriate sample geometries and materials will be purchased and modilied at the TRA facility for the experiments to be performed. Where possible, existing sample matcrial will be used. Laboratory space has been identified at the TRA facility. The CRAS sample preparation will be performed in TRA 604 Lab 113, and the measurements will be performed in TRA 603 Lab A103. 


\section{HEALTH AND SAFETY}

The EG\&G Idaho Safety Manual and Standard Practice Manual define the safety and training requirements for employees working in the laboratories. In particular, the Science and Technology Standard Practices, Section 2, define the specific applicable safety requirements. Designated personnel working on this program will be required to undergo training for radiation workers, radioactive material handler, and hazardous waste. The principal investigator has the responsibility to ensure that all work performed in the laboratories meets safety and environmental compliance requirements. An Independent Safely Review Group review will be performed to define project specific safety requirements. A standard spill control plan is associated with the laboratory where samples are prepared. Only sealed samples in unbreakable containt:rs will be used in the test laboratory.

The primary risk associated with performing the tasks for this project is radiation exposure. In the Radiation Work Permit (RWP), the TRA Radiological Engineering group will define the proper radiological controls associated with the tasks to be performed based on the radiation levels measured at the work site.

Dosimetry, time, distance, shielding, and necessary radiation monitoring will be used as necessary to limit radiation exposure to as low as reasonably achievable. To assist in the control of radioactive contamination, gloves, laboratory coats, protective clothing, and respiratory protection as required will be defined by the health physics technician (HP) in the RWP. All working areas will be marked, labeled, and cordoned off with the proper zone limits as required by the EG\&G Idaho Radiological Controls Manual and as directed by the HP. Alter work completion, all materials and equipment will be surveyed by the HP. 


\section{RESIDUALS MANAGEMENT}

The residuals associated with this project are soils containing nonhazardous waste (e.g., chlorine as $\mathrm{NaCl}$, iron, nickel, cobalt, and magnesium as iron or stainless steel) and hazardous solids (e.g., lead, cadmium, and mercury), which will be returned to the existing stocks. The lead, cadmium and mercury will be placed in small containers that will be cleaned for reuse. No specific hazardous wastes are produced as part of this project. 


\section{REFERENCES}

1. Oak Ridge National Laboratory, "MCNP-4, Monte Carlo Neutron and Photon Transport Code System," Radiation Shielding Information Center Computer Code Collection, CCC-200A/B, 1991.

2. EG\&G ORTEC, OMNIGAM-B30-BI Advanced Gamma-ray Spectrum Analysis Software, Oak Ridge, Tennessee.

3. E. W. Killian and J. K. Hostwell, "VAXGAP: A Code for the Routine Analysis of Gamma-ray Pulse-height Spectra on a VAX Computer," IEEE Transactions on Nuclear Science, Vol. 36, No. 1, 1989. 

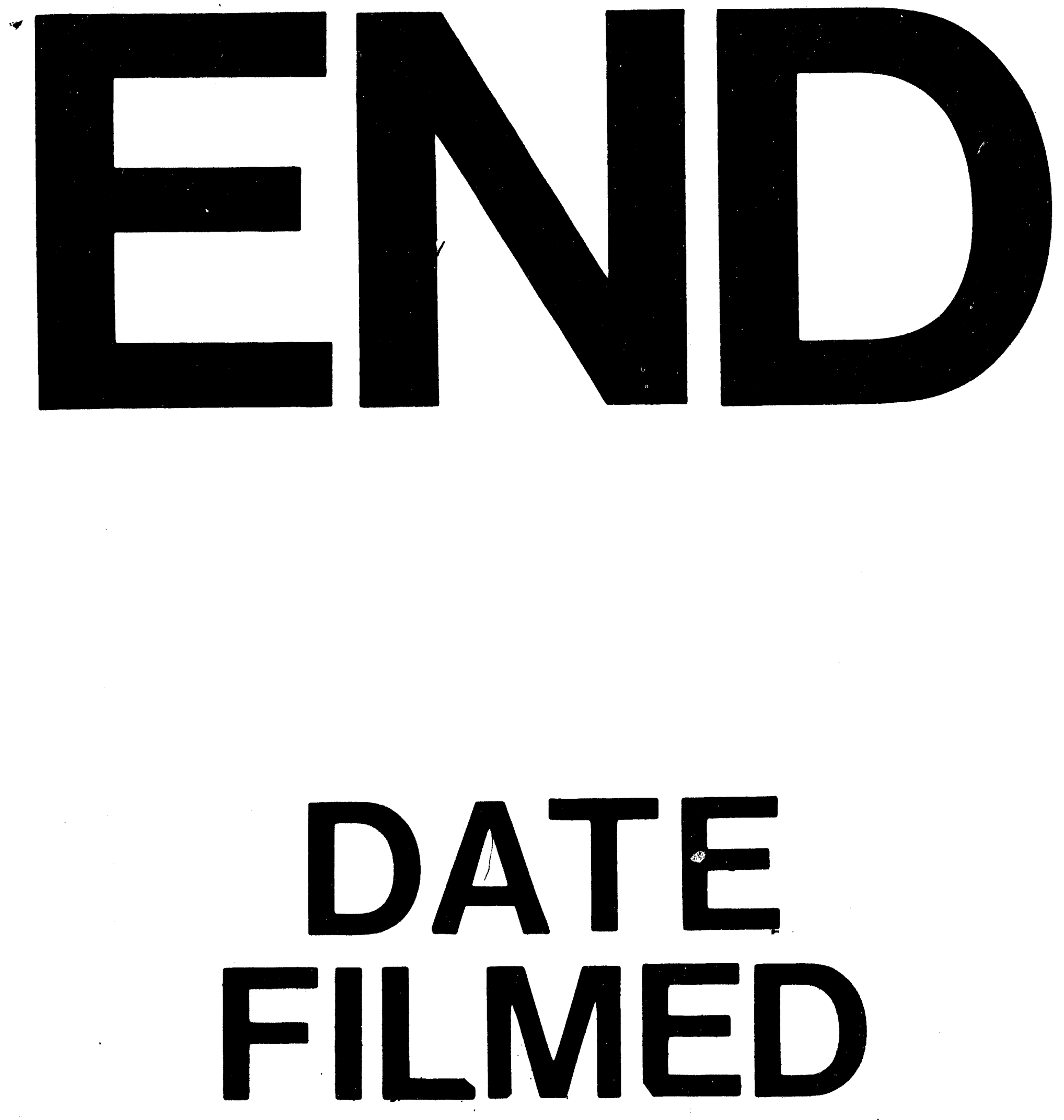

$$
12 / 28 / 93
$$


